\title{
Show and 'Tool': How lecture recording transforms staff and student perspectives on lectures in higher education.
}

\author{
Jill R D Mackay \\ Royal (Dick) School of Veterinary Studies \\ The University of Edinburgh \\ jill.mackay@ed.ac.uk \\ Twitter: @jilly_mackay
}

\section{Abstract:}

Lecture recording is sometimes considered a disruptive technology which has the potential to supplant the traditional higher education model through fundamentally changing how students are taught. Despite this, there is limited evidence that lecture recordings affect student attendance or attainment, and so it is not clear why lecture recording is considered so disruptive. An evaluation was run in a large Russell Group Institution in the UK in 2018 as it rolled out an institute-wide lecture recording programme. In this study, in-depth interviews with 13 staff members and free-text responses from 159 first-year student survey respondents were analysed using constructivist grounded theory to explore why lecture recording is viewed as disruptive, and what the implications of this are for teaching. Both staff and students were concerned with issues which happened inside the classroom (proximate) and wider issues about education (ultimate issues), but these concerns manifested differently between the groups. Overall, the act of recording a space was considered transformative, creating a digital artefact which was both highly valued by students as a 'tool' to improve their learning, but impacting on the overall 'show' that lecturers felt was a core aspect of the lecture. Ultimately, staff were also concerned that recordings 'canonised' the material, and made students too reliant on lectures, whereas students viewed the recordings as a safety net. The implications of this transformative power of recording for teaching are discussed. 
Keywords: improving classroom teaching; distance education and telelearning; pedagogical issues; teaching/learning strategies 
Introduction

Laurillard, (2008) observed that higher education has been 'on the brink' of being transformed by technology for a matter of decades. Lecture recording (variously 'lecture capture', 'lecture podcasting') has been discussed in terms of its effects on higher education for nearly twenty years (Gysbers, Johnston, Hancock, \& Denyer, 2011). When lecture recording definitions also include distance learning, such as models adopted by the Open University, then the effect on student learning has been explored since the late sixties (Zawacki-Richter \& Naidu, 2016). Regardless, recording facilities are becoming more widespread within higher education (Newton, Tucker, Dawson, \& Currie, 2014), and lecturing staff harbour a number of concerns about how it will affect learning and teaching (Bond \& Grussendorf, 2013; Chang, 2007). Lecture recording is sometimes referred to as a disruptive technology (Maree Gosper et al., 2008; Preston et al., 2010) with the potential to transform programme design (Gosper et al., 2010). This view is not necessarily shared by students who see technology enhanced learning (TEL) as more routine (Conole, de Laat, Dillon, \& Darby, 2008). Danneels, (2004) characterises 'disruptive technologies' as a novel technology or innovation which initially underperforms in a market prior to becoming the dominant force, displacing established technologies. In this way, a disruptive technology may provide the market with new benefits, or merely improvements over other methods, but importantly will supplant traditional methods in time. If we consider lecture recording to be a disruptive technology, with the potential to transform higher education, it is important we identify what it is we expect lecture recording is going to replace. An oft-proposed reason why lecture recording may be considered a disruptive technology is the idea that e-learning pedagogies can disaggregate learning from a traditional classroom context and thus supplant the traditional university model, devaluing the classroom experience through providing of resources outside of it (Anderson \& McGreal, 2012; Conole, 2013). In this study, I qualitatively explore staff and student perspectives on what is being 'disrupted' or changed by the implementation of lecture recording in a large Russell Group institution in Scotland. 


\section{Disruption to Student Attendance}

Lecturers are often concerned that student attendance for lectures will be negatively affected by the implementation of lecture recording, believing that personal interaction and engagement with lectures at the point of delivery is an important part of the pedagogical experience (Chang, 2007; Kwiatkowski \& Demirbilek, 2016). This may reflect some uncertainty surrounding the role of lecture recording in the student experience. Evidently distance learning is capable of providing this community aspect of education without face-to-face contact (Boyd \& Paterson, 2016; Rovai, 2002; Rovai \& Jordan, 2004), although it is acknowledged that distance learning students often feel disadvantaged, particularly at independent research stages of a programme (Ross \& Sheail, 2017). Lecture recording does represent one end of the blended learning scale, providing some learning materials in a virtual context outside of the classroom. Flipped classrooms, where students receive content prior to coming to discuss the content in class time, exist further along this scale, sometimes considered the most effective blended learning technique (Holley \& Oliver, 2010; López-Pérez, 2011), as students have the greatest opportunity to discuss with and engage with the lecturer. Ergo there is an argument for careful consideration as to the role of lecture recording, with an understanding that poor application of blended learning strategies can have a negative impact on student experience (Bothwell, 2016). In this case, the question of student attendance is one of whether students will 'bother' to turn up to lectures if given an alternative. One study explored the usage of lecture recording by students. In a focus group of ten students only one student felt that attendance would be affected if a lecture was scheduled at an unpopular time slot (Leadbeater, Shuttleworth, Couperthwaite, \& Nightingale, 2013). In this study, the students were also concerned that if small numbers of students stopped attending lectures, and recorded lectures were therefore blocked, this would unfairly penalise those students who intended to both attend lectures and use the recorded resources. Another study asked 517 students why they used recorded lectures with between $67-70 \%$ (depending on lecture recording type) agreeing that it could replace live 
attendance (Gorissen, Van Bruggen, \& Jochems, 2012), however this question was asked in the context of 'missed' lectures, rather than an active choice by the student not to attend. The confusion around the interpretation of this question has led to Gorissen et al occasionally being used to support the possibility of an effect of lecture recording on lecture attendance. Another study of 439 students found that the implementation of lecture recording resulted in $55 \%$ of students considering their attendance 'less than normal' and $10 \%$ of students said they stopped attending lectures entirely (Owston, Lupshenyuk, \& Wideman, 2011). There was no statistically significant difference in the grades between those students who felt their attendance has been affected by the provision of lecture recording. In other cases where academics were questioned about attendance after captured lectures they perceived no difference in their students' attendance (Chang, 2007). Other studies have found no significant effect of lecture recording on attendance in a variety of classroom situations (Toppin, 2011; Zhu \& Bergom, 2010). Reasons for student non-attendance at lectures is considered to be highly personalised, encompassing health concerns, personal preference, motivation, and external pressures such as part-time employment or carer status (Kottasz, 2005) and there is considerable work suggesting that the provision of extra resources, such as lecture recordings, do not alone encourage students to stop attending lectures (Gysbers et al., 2011). In my opinion, there is also often a subtle conflation between engagement and attendance in the lecture recording literature. Student engagement with higher education is complex and fundamentally emotional (Pekrun \& Linnenbrink-Garcia, 2012), and not necessarily positive. An attending student may not be engaging with the material, as some studies suggest students may spend up to $60 \%$ of their device-related time in 'off-task' activities (Ragan, Jennings, Massey, \& Doolittle, 2014). The evidence from the literature suggests that lecture recording may not be a disruptive technology through changing attendance, but perhaps through the perception of attendance, and how that perception links with perceptions of student engagement. 


\section{Disruption to Student Attainment}

Ultimately lecture recording aims to assist student learning. There are a number of possible mechanisms through which lecture recording can aid learning. It has been hypothesised that lecture recording allows for deeper engagement with course material (Zhu \& Bergom, 2010), and that students learn better through being able to control the speed of the lecture, e.g. pausing and resuming when desired (Dey, Burn, \& Gerdes, 2009). Students consider that lecture recordings help to clarify concepts discussed in class, and are convenient for the review of material (Toppin, 2011). Other studies have taken a more nuanced approach to how students utilise recorded lectures. It does not appear to be the case that the implementation of lecture recording raises performance across the cohort. In one study, which only captured the slides and audio, low-achievers viewed the lectures more frequently than high-achievers, suggesting they were attempting to master material they found difficult (Owston et al., 2011). Their methodology did not allow them to conclude whether the low-achievers benefited from the ability to review lectures. Another study (Leadbeater et al., 2013) found no observed difference in achievement across students who made use of lecture recordings, but did find that those students who were non-native English speakers or had learning adjustments made far higher use of the learning recordings. Again the methodology utilised did not allow the authors to state whether the lecture recordings allowed those students to match the performance of other students, but the uptake and usage of lecture recording suggests that this was a valuable resource for these students. Often evaluation of lecture recording relies on retrospectively investigating how learning occurred after implementation of lecture recording software. Future studies may benefit from students keeping a learning-log throughout a course to more accurately recording student behaviour, and longitudinal tracking to see how resource usage changes with time. This may be a key area where the lecture recording could act as a disruptive technology within education, but it will require guidance for students as to the use of lecture recordings, which up to now has been limited (Nordmann \& Mcgeorge, 2018). 


\section{Quality of Recordings and IT Support}

Another common concern regarding the implementation of lecture recording is the use of (yet another) IT system, a lack of training for staff and also associated issues regarding the quality of the recording provided to the student (Kwiatkowski \& Demirbilek, 2016). Sometimes this issue also incorporates accessibility, for example lecturers in Australia have been concerned regarding the students' ability to access the resource when in rural areas where internet is not easily available or regular (Chang, 2007). A small percentage (7\%) of Gorissen's (2012) student cohort found the video quality in one of their participating institutes poor enough to discourage uptake. In the qualitative aspect of Gorissen's study, students did not mention quality as one of their concerns with lecture recording but it was noted that students rarely watched the whole lecture in a sitting, preferring to skip backwards and forwards to watch the parts that interested them (Gorissen et al., 2012). Kwiatkowski and Demirbilek's study indicated that a potential challenge to the quality of a lecture could be when the student discussion element is particularly important as when there are no microphones directed at the students the audio quality of such discussions drops. Where technical issues become an insurmountable hurdle, we might consider it unlikely that lecture recording could become a disruptive force within higher education.

\section{Ethics and Intellectual Property Issues}

Lecture recording may be disruptive to higher education in an academic context, but there are also potential social disruptions surrounding how such data is captured, collated and shared. An oftraised concern from lecturers surrounds the protection of intellectual property (Kwiatkowski \& Demirbilek, 2016). Lecturers may feel as though the content, style and indeed the presentation of their lecture is integral not only to students' understanding but their own delivery, and that capturing this risks others mimicking or passing off such work as their own. Broadly, this issue dovetails with open educational resources and peer-observation in learning. Some have indicated that the production of open educational resources (OERs) can reduce the cost of maintaining a course after set up (Caswell, Henson, Jensen, \& Wiley, 2008), which has not necessarily been the 
experience of Edinburgh University staff working in distance-learning (MacKay et al., 2018). However open educational resource policies often corresponds with academic tradition (D'Antoni, 2009). D'Antoni noted that another intellectual property issue cropped up within the creation of OER and that was the lecturer's inappropriate usage of intellectual property through the use of media (e.g. images, videos or audio) that they did not own the copyright to. Widespread adoption of lecture recording will require a more widespread understanding of intellectual property rights among lecturers and a continued embrace of open education policies.

In Chang's (2007) study there was discussion of lecturers feeling more guarded during lecture recording. This manifested in different choices of stories to illustrate points as one lecturer stated: 'Mmm I'm on record here and could it come back to be used against me.'

This may be an unintended benefit of lecture recording. Lectures are not private spaces or 'off the record' if they are not being recorded. Regardless, the ethical and copyright issues surrounding lecture recording may be another possible route for disruption for the higher education model, encouraging stricter adherence to rules.

\section{Routes to Transformation}

Technology Enhanced Learning (TEL) has been referred to as an 'enduring myth' by Goodchild \& Speed, (2018), who also proposed that we are living in the 'fourth epoch' of TEL. The fourth epoch was characterised by the important political and social ramifications of implementing learning technology, which adds a new dimension to Svetsky \& Moravcik's (2018) discussion of the technical barriers of TEL. The way in which a technology is used in learning also reflects how that technology impacts society, both within the educational institutions, but also more widely. Often concerns about TEL are concerns that teaching will fundamentally change (Garrison \& Kanuka, 2004; Lawton \& Katsomitros, 2012). The 'disruptive technology' model of TEL requires that any evaluation of TEL implementations should also consider the social context and the transformative elements of 
adopting such technologies. What is the social context of implementing lecture recording, and how does it affect the educational environment? This study was part of a larger programme of evaluation of the implementation of a lecture recording system at the University of Edinburgh. In this part of the evaluation, I was interested principally in two main research questions: how does the implementation of lecture recording transform the lecture space, if at all?; and how do the agents within a recorded lecture respond to that change? 


\section{Data and Methodology}

Ethics Approval:

This study was approved by the School of Education Ethics Sub-Committee at the University of Edinburgh, reference number 1218.

\section{Ontological and Epistemological Stances}

Qualitative data analysis can be a powerful tool for understanding human behaviour, but the underlying assumptions, or biases, of the researchers are often not made explicit (Braun \& Clarke, 2006). As an interdisciplinary researcher, I would state that I adhere to a constructivist epistemology with a realist ontological stance, in that if there is an objectivist 'truth' to the natural world, it can only be varyingly described by people, in the context of their shared knowledge.

\section{Participants and Recruitment}

As this project was part of a larger implementation of a lecture recording system at the institution a range of data sources were available to the researcher including the previous year's course evaluation questionnaires across the institution, analytics from the recording service, regular meetings of academic groups, and the policy consultation data, service feedback, the JISC digital tracker and visits to user groups. As this data had not been collected with express permission for research they were used to refine the research question(s) and to inform sampling.

Staff members were invited to participate via email cascaded through 'academic champions' within each user-group. A participant's status was only known to the principle investigator and not the champions or implementation team. For staff, data was collected through unstructured interviews. The interviewer was the author, an early career academic of white ethnic background and working within STEMM education research. Recruiting was maintained in a snowball sampling fashion, and included a non-consecutive 14-day period of industrial action which impacted upon the themes emerging from the analysis. Interviews were conducted in private, most commonly in the participant's office, and were recorded via Dictaphone and later transcribed in full via a third party. 
In total, thirteen staff members were interviewed including academics from Lecturer to Professorial level, one visiting academic, and one member of professional services, and recruitment stopped when no new themes were emerging from the interviews. Three participants elected to follow up at different stages via email with further reflections, which were incorporated into the consideration of the data but not directly analysed.

The student experience was not captured through unstructured interviews as it was thought that one-to-one interviews with an unfamiliar member of staff, no matter how well-meaning, may not have been a comfortable experience for the student participant. As industrial action was likely to occur prior to the examination period, and collecting data on students would not be appropriate near the examination diet, I devised a survey to explore student attitudes and beliefs about lecture recording. The survey was sent to all first year students from eight schools within the institution. The schools were purposefully selected based on information within the Course Evaluation Questionnaires to sample across a range of user experiences, e.g. schools where students had excellent experiences with lecture recording, and schools where students expressed regular frustration at the lack of lecture recording facilities. First year students were sampled to avoid conflating the results of the present lecture recording system with other systems schools may have used. The survey opened on the 2nd May, 2018 and a reminder was circulated on the 14th May. The survey closed on the 1st June (duration: 29 days). It was sent to 2125 first year students across eight schools. A total of 295 students responded (13.8\% response rate) and all respondents answered all questions. There was no need to exclude any respondents. Students were asked to rate how frequently they had made use of lecture recordings in full, or in part, over the last academic year, and how likely they felt they were to change their behaviours in recorded lectures, and how highly they valued lectures as a revision tool. In this study we report on the findings from the free text question "is there anything you would like to tell us about your experiences with recorded lectures, good or bad?" which 159 students responded to. 
Following the survey, a focus group was conducted with student representatives, however the proximity to the exam period of the focus group meant that only two students were able to attend. The focus group was conducted by the same researcher and an additional research assistant who had graduated from an undergraduate degree the year before, and was closer in age to the student participants. During the focus group, the participants were introduced to some of the themes raised within the student survey and the staff interviews and the participants reflected on these. Again, the discussion was recorded via Dictaphone and transcribed later by a third party. Despite the small number of participants, the reflections on previous themes, and inherent value within the student discussion, lead me to include this data in the analysis.

\section{Analysis}

Constructionist grounded theory methods were used to analyse the data and as per this approach, data is used to develop a theoretical analysis throughout the project (Charmaz 2008). As such, prior to data collection, potential themes were discussed in the mixed committees that championed engagement with the new lecture recording system as a form of participant-checking. These committees included academics, support staff, student interns, student representatives and student union sabbatical officers. Qualitative coding software (NVivo, QSR International Pty Ltd., Version 11, 2016) was used to track commonly expressed ideas or beliefs (themes) and preliminary analytic notes (memos) regarding how themes were expressed. Data was coded iteratively with each new addition of data and then refined through reading of the literature surrounding lecture recording challenges. At several stages the themes and the overall theories being generated from the data were reported back to the mixed committees and were agreed upon in their interpretation and validity from both staff and student perspectives. 
Results

The analysis of the data was initially very easily separated into two common sets of issues which existed across both staff and student groups. There were proximate issues (from the latin proximus or 'nearest'), which occurred within the lecture space, and ultimate issues (from the Latin ultimus or 'farthest'), which detailed challenges outside of the lecture context. However, there were notable differences in what themes both groups considered in these spaces. My analysis was therefore that there was a deeper conflict surrounding what lectures were for, and how they were to be used between staff and students. The disparity within each user group's ultimate and proximate concerns may reflect greater challenges within learning and teaching (Figure 1). The 'theory' constructed in this analysis is that recording a lecture transforms the act occurring within that teaching space into something else, and in this way, lecture recording was disruptive as it affected both proximate and ultimate issues for each group in different manners.

Figure 1: Summary model of concerns across staff and students

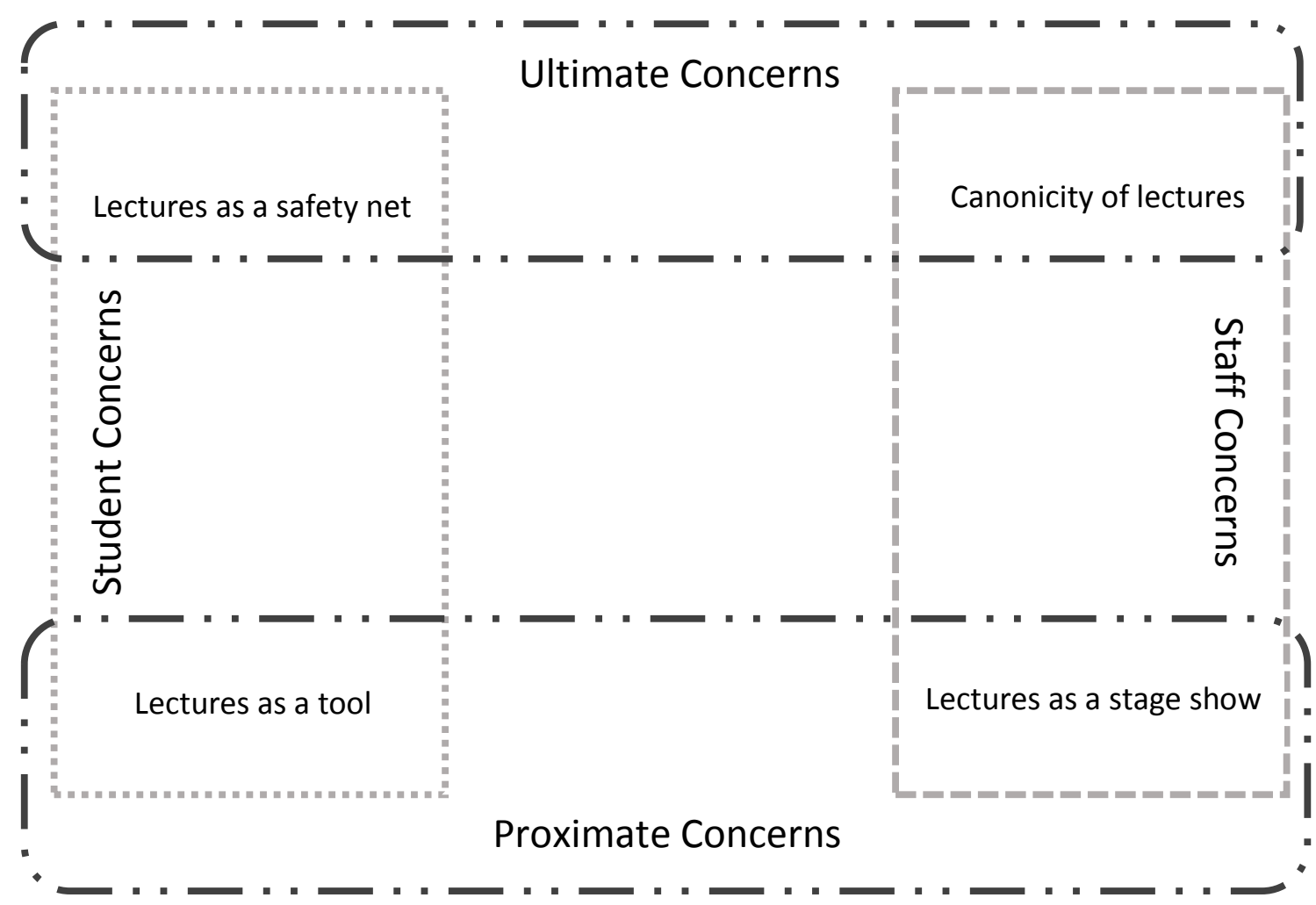


Proximate Issues: The Show and the Tool

Within the proximate concerns which arose during the lecture space, there was an interesting demarcation between staff and student participants regarding what they saw the lectures as being 'for'. Staff participant N summarised the role of a lecture thusly:

In terms of information distribution, it's not a particularly effective method in terms of learning skills, but I suppose it's more almost an entertainment in some way. Yes, but it's to inspire them, it's to enthuse them, it's to make them excited because of the way the subject works. - Staff Participant $\mathrm{N}$

By contrast, not a single student within the survey discussed the 'entertainment' value of a lecture. Within the survey, students focussed on lectures as mainly a means to an end, and that end was often framed as examination. Lecture recordings therefore were seen as a highly valuable tool for study and revision.

The recorded lectures are invaluable as a learning tool to revisit any lectures where I did not fully understand the material during the class. I also appreciate that recorded lectures are available throughout the school year to be accessed when required. Student Survey Respondent

The lecture recordings are great to look back on the information a month or so later for revision. It is also beneficial for when you don't quite understand something during the live lecture. - Student Survey Respondent

I raised the idea of 'entertaining' lectures with the participants in the student focus group, and it did not provoke strong feeling among the student participants. With one student reflecting on the idea of lecturers being 'entertaining' by saying:

To be honest, I don't know how I would really find out [if a lecturer was entertaining] beforehand, unless there's really well preserved gossip, ... I just showed when I was supposed to and listened to what they had to say. - Student Focus Group Participant A 
This mismatch between the student and staff perspectives on what happens in the lecture reflects some of the debates regarding teaching within the literature. Lectures are said to be 'teacher focussed' and can be considered a very economical method of teaching (Banning, 2005) due to the high number of students reached at any one time. It is also typically the method that current STEM lecturers learned from and, if they enjoyed that experience, were likely to favour themselves (Oleson \& Hora, 2014). On the other hand, despite the prevalence of lectures, students often find them difficult to follow (Gibbs, 1981). In one study exploring the performance of nursing students, lectures did not promote enjoyment of a difficult subject but also did not establish other study skills (McKee, 2002). These limitations are not necessarily due to a lack of study skills. Didactic teaching makes up a large proportion of the continuing professional development of doctors, who may have primarily learned theory and passed their own professional degrees through the use of didactic teaching, and yet the retention of knowledge from such sessions is poor (Davis et al., 1999). 'Academic boredom' among students has been found to be a predictor of surface approaches to learning (Sharp, Hemmings, Kay, \& Sharp, 2017), suggesting that there is some merit to the staff description of entertaining students, and the staff participants were very conscious of the need to keep students engaged.

there's always a little bit of trade off, we can spend a lot of time talking about fun stuff in less detail and not have enough time to cover more technical material which seems a little bit more boring, or we can do only technical stuff, but that's clearly a terrible idea because everyone will fall asleep - Staff Participant Y

Students greatly valued lecture recording because, in their view, it widened the toolset available to them. Technical issues, or other factors which made recorded lectures less predictable were therefore extremely frustrating to students. 
It would be a good idea for all of the lecture recordings to be titled, in order to make it easier and quicker when trying to find a specific one to watch. - Student Survey Respondent

Some lecturers do not know how to use the recording system (the red button) some lecturers don't use the microphone (sometimes they dont use it because it broken) and so the recording has no sound, and sometimes you thought it was going to be recorded but then it becomes pointless because of the lack of sound - Student Survey Respondent A number of the staff participants used the metaphor of a live play or 'gig' when discussing their lecturing. In keeping with this, they were often less concerned with technical issues, viewing them more as abstract issues which would be sorted 'eventually'. For example, one staff participant finished their interview by raising the following point:

one very, very minor practical thing, which was, because of the scheduling of the recordings, they come on automatically, that doesn't necessarily coincide very well with my lecture start and stop. - Staff Participant $\mathrm{K}$

While several students in the survey commented on the same issue:

However sometimes lecturers do not follow this precise timing so it would be good if they could chose when to start/ end the recording. - Student Survey Respondent Also having such a fixed schedule for recording means that parts of lectures are often cut off if lectures start early or finish late. - Student Survey Respondent

The impact of technical issues are certainly lesser for the lecturer, who will give a similar lecture in another course or next year, but for the students in that class technical issues were seen to deprive them of a highly-valued resource. This did create some tensions between staff and students.

Some lecturers cannot be bothered to set it up and just pass it off as the system not working - Student Survey Respondent 
Whereas, staff often discussed whether they ever truly gave the same lecture 'twice', and highlighted how the student engagement would change the content.

you might have a lecture that you gave last year, but when give it next year it will be a bit different, because you might see that the audience are picking up on it or not picking up on it. So, you might do it a different way. You might forget bits of it. - Staff Participant $N$

In these data, the central challenge for incorporating lecture recording into the learning skillset of the student was about the guidance they received, and their ability to rely on the lecturers using the technology consistently. Although staff were concerned with student engagement, and felt pressure to produce entertaining lectures, students did not, in this work, express a desire for more entertainment. This may be that lectures are engaging enough, or that students do not view this as an important component of their learning. The greatest proximate issue for students was the need for more predictable and usable tools to supplement their learning.

\section{Ultimate Issues: The Canon and the Safety Net}

Staff were not insensitive to the importance students placed on lectures as a tool for learning, but they did hold some concerns about the true importance of lectures for learning. Staff worried that lecture material would become the primary source for learning, both because recordings would make lectures more easily accessible than other texts, but also because going to the effort of recording the lecture afforded it increased importance.

I think, as soon as you have a recorded lecture, that then becomes canonical and it's seen as something people can, sort of, reference and quote verbatim, and I'm not keen on that. - Staff Participant K 
So previously I've had texts from my PowerPoint slides regurgitated right back in an answer, I don't like that. More recently I've seen cases where there's something that's not on the slide but exactly the same phrases are used by several students, and I think 's that something I said? How come they've all got that saying?' So yeah, this is one of my big issues with recording - Staff Participant U

There were also worries that students would miss some vital aspect of learning because of the recordings, even though these concerns were sometimes apocryphal, such as for Staff Participant W:

I have a colleague who feels strongly that it is a disadvantage to students to record lectures because it will "make them" not take the lecture part seriously. . . A colleague has expressed a view that it is preventing the students developing their note taking skills. ... Another colleague expressed the view that some students will go back to their residence or library in the evening and they will listen to the lecture again and will take notes, wherein they should be reading beyond the lecture or reading textbooks. Staff Participant W

On the other hand, students did not worry about changes to their ultimate learning strategies, but instead about personal issues which may affect them.

It's also helpful if students have no choice but to work and miss a lecture or if we pick up one of the bugs that invariably knocks you over at some point during the semester there isn't then the added stress of taking time to get well because you can always go back and 'attend' the lecture once you're well enough again.- Student Survey Participant The idea of lecture recordings acting as a 'safety net' was also very prevalent among students who were carers, or had other challenges accessing a university education. These students talked about 
the stress of missing a lecture, again relating to the importance students place on lectures as a tool for progressing through university.

When lectures are made available to view at a later date, they can be very helpful and even crucial for people with mental health problems or disabilities that make attending *every* lecture difficult. - Student Survey Participant

I have a [child who] requires frequent hospital admission and extra care at home. Having access to the recorded lectures, that I may have missed, has allowed me to keep on top of my studies during these times, without the worry and anxiety of missing vital topics/lectures. For people in the same situation as me it is an invaluable resource and one that I feel should be rolled out across the university - Student Survey Participant This should be considered in light of the prevalence and incidence of anxiety and depression and suicidal thoughts (Mortier et al., 2018) among university students. We know that students with conditions such as ADHD show higher incidences of anxiety and depression, and can find following lectures more challenging (Anastopoulos et al., 2018). 
Disruptive Technology: The Transformative Power of Recordings

One of the key findings of this piece of research was a pervasive belief that recordings fundamentally changed aspects of the lecturing space. This was most obvious within the staff participants, where both proximate and ultimate concerns could be transformed by the additional presence of recordings. The ubiquity of recording in our current society is unmatched from any point in history, and the uses of recordings in our social spaces can serve many purposes. van Dijck, (2008) argued that photography has recently become a way to curate identity formation. Similarly, tourists may use cameras to tell themselves a narrative about their vacation, rather than creating messages to convey to others (Belk \& Hsiu-yen Yeh, 2011). Even highly ritualised images, such as family snapshots, have been changed with the increasing prevalence of cameras, as younger family members become curators of the family image (Pritz, 2011) and in-situ recordings become preferred to posed shots (Le Moignan, Lawson, Rowland, Mahoney, \& Briggs, 2017). The sense of 'self' that can be linked to image capture is perhaps more established within the personal world than within the professional world, and this change was acknowledged by some participants.

I think, it's probably something that maybe younger researchers in general are more comfortable with, just because we're using technology more. I think [my field] are often quite backward at the use of technology, there are lots of exceptions.

\section{- Staff Participant $K$}

And even small changes in delivery, such as the size of the lecturer's image on the screen could change the way the lecturer felt about the recording. 
I don't entirely like being blown up to full screen, to be honest with you... . I

would prefer to be smaller. I wonder, what benefits do the students get from me

full screen, because it's really my voice, isn't it, they need to see?

- Staff Participant A

The way in which recording can drive this change was discussed by staff participant $\mathrm{S}$ who considered whether a new type of hidden curriculum (Snyder, 1971) message was being delivered to students when an institution went to the effort of recording lectures.

For me, the worst way possible to envisage why we need this process is because the content of the lecture is important and the student needs to know this content and therefore they need to be able to get hold of it, because if they don't get this content and there's so much there, they will not be able to pass the assessment. For me, that is taking a 21st Century piece of pedagogical equipment and technology and just going for rote learning and actually that's making the students dependant on the lecture, it makes the lecture almost redundant as a form, because as soon as it's recorded and captured once, what would be the point in doing it again? - Staff Participant S

Discussion

The key transformative ability of lecture recording observed in this study was the formalisation or canonisation of material, which staff were inherently deeply uncomfortable with. There was also a more literal transformation of the teaching act into a digital object which could be referenced and returned to, which staff felt discouraged students from focussing on skill development. In some respects, the lecturing act is traditionally always transformed into an object through the act of notetaking (Peper \& Mayer, 1978). The act of note-taking is considered to improve cognitive skills (Piolat, Olive, \& Kellogg, 2005), and has been argued to be most beneficial when writing pen-to-paper, as 
opposed to making digital notes (Mueller \& Oppenheimer, 2014). Simply having access to notes for review has long been recognised as beneficial for learning (Carter \& Van Matre, 1975), even if the students did not take those notes themselves. There is certainly an interaction between how lectures are 'objectified' and how students learn, but as there is also limited guidance in how students are supposed to use lecture recordings (Leadbeater et al., 2013; Nordmann \& Mcgeorge, 2018), it is difficult to disentangle these effects. One consideration is that this study focussed on first year undergraduates, who in theory are at the start of their academic study, and are not yet grasping the 'shows how' and 'does' elements of skill development (Miller, 1990; Schoenfeld-Tacher \& Sims, 2013). The students who engaged with this study did show some evidence of focussing on 'knowledge' acquired through lectures, as opposed to skills, in their relating their use of recorded lectures to their exam diet, but this requires further study. It may be worth questioning whether staff clearly communicate to students what they expect a lecture is for, and what students should be doing in that space.

This study proposes that the process of recording a teaching space can transform the act of teaching within it, possibly commodifying it by creating a digital object. With this new knowledge, we must ask 'so what?' Does the transformational property of lecture recording matter in terms of higher education delivery? In some senses, this depends on the ontological and epistemological stance of the reader. A positivist leaning reader may consider the attitudes or intentions of the lecturer immaterial, as the lecture itself has a specific purpose outwith how staff and students consider it. This was touched on by Knewstubb \& Bond, (2009) who explored 'communicative alignment' in lectures, or the similarities and dissimilarities of what the lecturer intends to say and how the students perceive that intention. As the student is ultimately being assessed on the lecturer's intention, often in a high-stakes scenario (Boud \& Falchikov, 2007), any misunderstanding of the lecturer's intention can carry penalties. Knewstubb \& Bond demonstrate with a particular teaching exercise how students can focus on the goal, and in that context, used recordings of lectures to 
facilitate discussion. Having a version of the teaching activity which can be returned to by both actors may be able to greater facilitate communicative alignment, helping students and staff clarify what was said. In this stance, the transformative feeling of being recorded is perhaps less impactful. The object created by recording can facilitate communication.

Another lens through which to view the recorded lecture object is that of 'messy objects'. These are complex and multi-constructed entities that communicate knowledge in actor-network theory (Scoles, 2018). This lens may be a useful way to view the recordings of lectures as an artefact which represents the lecturer and students' collective interpretation of the lecturing act. In this way, both staff and students have shared responsibility for the production, and the recordings may 'transform' the object from a co-constructed stance to a boundary object which creates transition from student to practitioner. Staff discussed their worries about students citing lectures in examinations, or having their own mistakes amplified through the repetition that recordings allow for. The implementation of lecture recording may be an opportunity to explicitly reframe the lecture as a jointly-negotiated space between the lecturer and students, encouraging both parties to come to a mutual understanding. Perhaps staff and students could jointly review key recordings to revisit topics, particularly in revision sessions. In this sense, lecture recording may be a disruptive TEL.

\section{Criticisms of the Study}

While the findings of this research were found reliable by other researchers within the institute, and agreed upon by participants, the findings may not be entirely generalisable. As previously mentioned, the student participants of this study were in first year. If higher education is viewed as a journey through which student perceptions and practice grows closer to staff practice (an academic literacies model, see Lea \& Street, 2006), then these student participants' practice would arguably be 'furthest from' the practice we would expect in later years. With this being said, staff did not present their concerns as concerns with early-year students but rather larger concerns with way in 
which lecture recording impacted all students. Additionally, some of the participant checking came from students in more advanced years, and they did not raise concerns that first years were completely unrepresentative of the undergraduate perspective.

It is possible that the findings of this study can only be applied in the context of this specific institute. More work is needed in a variety of contexts, given research suggesting that the benefits of lecture recording can be greatest for students from widening access backgrounds, carers, non-native language speakers and those with learning adjustments (Gosper et al., 2010; Leadbeater et al., 2013). There is also, in the authors' opinion a greater need for robust qualitative work in this area. Lecture recording is a contentious issue, which in this study elicited some conflicting worries from staff regarding the theatre versus the purpose of a lecture. It is important that we explore why these issues surrounding technology enhanced learning provoke such strong opinions, and how these may be barriers to successful uptake. The theory generated in this study, however, can be applied in different institutions and across different groups, and so further work is needed to explore how staff and students can work with the transformed lecture space. Ultimately, TEL aims to enhance learning, and as highlighted by Goodchild \& Speed, (2018), this must be understood within the social context of learning. It has been argued that individual higher education institutions have unique cultures (Aparicio, Bacao, \& Oliveira, 2016; Bergquist \& Pawlak, 2008) and so this work will need to be repeated elsewhere.

\section{Conclusions}

Lecturing staff and students in a large Russell Group university demonstrated their concerns around lecture recording in different ways. Staff were particularly concerned about the transformative properties of lecture recording, particularly where this created a 'canonised' object which could limit students' ability to acquire skills. Conversely, first year students greatly appreciated the provision of 
the recording object as a resource to facilitate their learning. Implementations of lecture recording should therefore be done with a view to creating a joint understanding of how the lecture recording object should be used by all parties in order to provide effective tools for learning.

Acknowledgements

The author would like to acknowledge the helpful comments of Anna Wood and Kirsty Hughes on earlier versions of the manuscript. 
References

Anastopoulos, A. D., DuPaul, G. J., Weyandt, L. L., Morrissey-Kane, E., Sommer, J. L., Rhoads, L. H., ... Gudmundsdottir, B. G. (2018). Rates and Patterns of Comorbidity Among First-Year College Students With ADHD. Journal of Clinical Child and Adolescent Psychology, 47(2), 236-247. http://doi.org/10.1080/15374416.2015.1105137

Anderson, T., \& McGreal, R. (2012). Disruptive Pedagogies and Technologies in Universities. Journal of Educational Technology and Society, 15(4), 380-389.

Aparicio, M., Bacao, F., \& Oliveira, T. (2016). Cultural impacts on e-learning systems' success. Internet and Higher Education, 31, 58-70. http://doi.org/10.1016/j.iheduc.2016.06.003

Banning, M. (2005). Approaches to teaching: Current opinions and related research. Nurse Education Today, 25(7), 502-508. http://doi.org/10.1016/j.nedt.2005.03.007

Belk, R., \& Hsiu-yen Yeh, J. (2011). Tourist photographs: signs of self. International Journal of Culture, Tourism and Hospitality Research, 5(4), 345-353. http://doi.org/10.1108/17506181111174628

Bergquist, W. H., \& Pawlak, K. (2008). Engaging the six cultures of the academy: revised and expanded edition of the four cultures of the academy (Second). San Francisco: Jossey-Bass.

Bond, S., \& Grussendorf, S. (2013). Staff attitudes to lecture capture. The London School of Economics and Political Science.

Bothwell, E. (2016). US blended learning students 'least engaged with teaching' | THE News. Retrieved 15 November 2016, from https://www.timeshighereducation.com/news/us-blendedlearning-students-least-engaged-teaching

Boud, D., \& Falchikov, N. (2007). Introduction: Assessment for the longer term. In Rethinking Assessment in Higher Education: Learning for the Longer Term (pp. 3-13). Routledge.

Boyd, S., \& Paterson, J. (2016). Postgraduate peer tutors supporting academic skills in online programmes. Journal of Learning Development in Higher Education, $0(0)$.

Braun, V., \& Clarke, V. (2006). Using thematic analysis in psychology. Qualitative Research in Psychology, 3(2), 77-101. http://doi.org/10.1191/1478088706qp063oa

Carter, J. F., \& Van Matre, N. H. (1975). Note taking versus note having. Journal of Educational Psychology, 67(6), 900-904. http://doi.org/10.1037/0022-0663.67.6.900

Caswell, T., Henson, S., Jensen, M., \& Wiley, D. (2008). Open educational resources: Enabling universal education. International Review of Research in Open and Distance Learning, 9(1), 111.

Chang, S. (2007). Academic perceptions of the use of Lectopia: A University of Melbourne example. ICT Providing Choices for Learners and Learning Proceedings Ascilite Singapore 2007, (2003), 135-144.

Conole, G. (2013). MOOCs as disruptive technologies: strategies for enhancing the learner experience and quality of MOOCs. RED - Revista de Educación a Distancia, 39, 1-17.

Conole, G., de Laat, M., Dillon, T., \& Darby, J. (2008). 'Disruptive technologies', 'pedagogical innovation': What's new? Findings from an in-depth study of students' use and perception of technology. Computers and Education, 50(2), 511-524.

http://doi.org/10.1016/j.compedu.2007.09.009 
D'Antoni, S. (2009). Open Educational Resources: reviewing initiatives and issues. Open Learning: The Journal of Open and Distance Learning, 24(1), 3-10. http://doi.org/10.1080/02680510802625443

Danneels, E. (2004). Disruptive technology reconsidered: A critique and research agenda. Journal of Product Innovation Management, 21(4), 246-258. http://doi.org/10.1111/j.07376782.2004.00076.x

Davis, D., O’Brien, M. A. T., Freemantle, N., Wolf, F. M., Mazmanian, P., \& Taylor-Vaisey, A. (1999). Impact of Formal Continuing Medical Education. JAMA: The Journal of the American Medical Association, 282(9), 867-874. http://doi.org/10.1001/jama.282.9.867

Dey, E. L., Burn, H. E., \& Gerdes, D. (2009). Bringing the classroom to the Web: Effects of using new technologies to capture and deliver lectures. Research in Higher Education, 50(4), 377-393. http://doi.org/10.1007/s11162-009-9124-0

Garrison, D. R., \& Kanuka, H. (2004). Blended learning: Uncovering its transformative potential in higher education. Internet and Higher Education, 7(2), 95-105.

http://doi.org/10.1016/j.iheduc.2004.02.001

Gibbs, G. (1981). Twenty Terrible Reasons for Lecturing. In SCED Occasional Paper No. 8. http://doi.org/10.1016/B978-0-12-800959-8.00021-3

Goodchild, T., \& Speed, E. (2018). Technology enhanced learning as transformative innovation: a note on the enduring myth of TEL. Teaching in Higher Education, 0(0), 1-16. http://doi.org/10.1080/13562517.2018.1518900

Gorissen, P., Van Bruggen, J., \& Jochems, W. (2012). Students and recorded lectures: Survey on current use and demands for higher education. Research in Learning Technology, 20(3), 297311. http://doi.org/10.3402/rlt.v20i0.17299

Gosper, M., Green, D., McNeill, M., Phillips, R., Preston, G., \& Woo, K. (2008). The Impact of WebBased Lecture Technologies on Current and Future Practices in Learning and Teaching. Australian Learning and Teaching Council.

Gosper, M., McNeill, M., Phillips, R., Preston, G., Woo, K., \& Green, D. (2010). Web-based lecture technologies and learning and teaching: A study of change in four Australian universities. Australasian Journal of Educational Technology, 26(8), 251-263. http://doi.org/10.1080/09687769.2010.529111

Gysbers, V., Johnston, J., Hancock, D., \& Denyer, G. (2011). Why do Students still Bother Coming to Lectures, When Everything is Available Online? International Journal of Innovation in Science and Mathematics Education, 19(2), 20-36.

Holley, D., \& Oliver, M. (2010). Student engagement and blended learning: Portraits of risk. Computers and Education, 54(3), 693-700. http://doi.org/10.1016/j.compedu.2009.08.035

Knewstubb, B., \& Bond, C. (2009). What's he talking about? the communicative alignment between a teacher's intentions and students' understandings. Higher Education Research and Development, 28(2), 179-193. http://doi.org/10.1080/07294360902725058

Kottasz, R. (2005). Reasons for Student Non-Attendance at Lectures and Tutorials: An Analysis. Investigations In University Teaching And Learning, 2(2), 5-16.

Kwiatkowski, A. C., \& Demirbilek, M. (2016). Investigating Veterinary Medicine Faculty Perceptions of Lecture Capture: Issues, Concerns, and Promises. Journal of Veterinary Medical Education, 43(3), 1-8. http://doi.org/10.3138/jvme.0615-090R1 
Laurillard, D. (2008). Digital technologies and their role in achieving our ambitions for education. Institute of Education, University of London. UCL.

Lawton, W., \& Katsomitros, A. (2012). MOOCs and disruptive innovation: The challenge to HE business models. The Observatory on Borderless Higher Education, 2011(August 2011), 1-10. http://doi.org/10.1080/1361457042000186967

Le Moignan, E., Lawson, S., Rowland, D. A., Mahoney, J., \& Briggs, P. (2017). Has Instagram Fundamentally Altered the 'Family Snapshot'? Proceedings of the $2017 \mathrm{CHI}$ Conference on Human Factors in Computing Systems - CHI '17, 4935-4947. http://doi.org/10.1145/3025453.3025928

Lea, M. R., \& Street, B. V. (2006). The 'Academic Literacies' Model: Theory and Applications. Theory Into Practice, 45(4), 366-377. http://doi.org/10.1207/s15430421tip4504

Leadbeater, W., Shuttleworth, T., Couperthwaite, J., \& Nightingale, K. P. (2013). Evaluating the use and impact of lecture recording in undergraduates: Evidence for distinct approaches by different groups of students. Computers and Education, 61(1), 185-192.

http://doi.org/10.1016/j.compedu.2012.09.011

López-Pérez, M. (2011). Blended learning in higher education: Students' perceptions and their relation to outcomes. Computers \& Education, 56(3), 818-826. http://doi.org/10.1016/j.compedu.2010.10.023

MacKay, J. R. D., Paterson, J., Sandilands, V., Waran, N. K., Lancaster, B., \& Hughes, K. (2018). Lessons Learned from Teaching Multiple Massive Open Online Courses in Veterinary Education. Journal of Perspectives in Applied Academic Practice, 6(2), 22-40.

McKee, G. (2002). Why is biological science difficult for first-year nursing students? Nurse Education Today, 22(3), 251-257. http://doi.org/10.1054/nedt.2001.0700

Miller, G. E. (1990). The assessment of clinical skills/competence/performance. Academic Medicine, 65(9), S63-7. http://doi.org/10.1097/00001888-199009000-00045

Mortier, P., Cuijpers, P., Kiekens, G., Auerbach, R. P., Demyttenaere, K., Green, J. G., ... Bruffaerts, R. (2018). The prevalence of suicidal thoughts and behaviours among college students: A metaanalysis. Psychological Medicine, 48(4), 554-565. http://doi.org/10.1017/\$0033291717002215

Mueller, P. A., \& Oppenheimer, D. M. (2014). The pen is mightier than the keyboard: Advantages of longhand over laptop note taking. Psychological Science, 25(6), 1159-1168. http://doi.org/10.1177/0956797614524581

Newton, G., Tucker, T., Dawson, J., \& Currie, E. (2014). Use of Lecture Capture in Higher Education Lessons from the Trenches. TechTrends, 58(2). http://doi.org/10.1007/s11528-014-0735-8

Nordmann, E., \& Mcgeorge, P. (2018). Lecture capture in higher education: time to learn from the learners. Psyarxiv Preprints, (May). http://doi.org/10.17605/OSF.IO/UX29V

Oleson, A., \& Hora, M. T. (2014). Teaching the way they were taught? Revisiting the sources of teaching knowledge and the role of prior experience in shaping faculty teaching practices. Higher Education, 68(1), 29-45. http://doi.org/10.1007/s10734-013-9678-9

Owston, R., Lupshenyuk, D., \& Wideman, H. (2011). Lecture capture in large undergraduate classes: Student perceptions and academic performance. Internet and Higher Education, 14(4), 262268. http://doi.org/10.1016/j.iheduc.2011.05.006

Pekrun, R., \& Linnenbrink-Garcia, L. (2012). Academic Emotions and Student Engagement. In S. L. Christenson, C. Wylie, \& A. L. Reschly (Eds.), Handbook of Research on Student Engagement 
(pp. 259-282). Springer Science and Business Media B.V. http://doi.org/10.1007/978-1-46142018-7

Peper, R. J., \& Mayer, R. E. (1978). Note taking as a generative activity. Journal of Educational Psychology, 70(4), 514-522. http://doi.org/10.1037/0022-0663.70.4.514

Piolat, A., Olive, T., \& Kellogg, R. T. (2005). Cognitive effort during note taking. Applied Cognitive Psychology, 19(3), 291-312. http://doi.org/10.1002/acp.1086

Preston, G., Phillips, R., Gosper, M., McNeill, M., Woo, K., \& Green, D. (2010). Web-based lecture technologies: Highlighting the changing nature of teaching and learning. Australasian Journal of Educational Technology, 26(6), 717-728. http://doi.org/10.14742/ajet.v26i6.1038

Pritz, L. (2011). Disturbing fine memories? An empirical study of young people's camphone family pictures. Photographies, 4(2), 191-207. http://doi.org/10.1080/17540763.2011.593949

Ragan, E. D., Jennings, S. R., Massey, J. D., \& Doolittle, P. E. (2014). Unregulated use of laptops over time in large lecture classes. Computers \& Education, 78, 78-86.

http://doi.org/10.1016/j.compedu.2014.05.002

Ross, J., \& Sheail, P. (2017). The 'campus imaginary': online students' experience of the masters dissertation at a distance. Teaching in Higher Education, 2517(May), 1-16. http://doi.org/10.1080/13562517.2017.1319809

Rovai, A. P. (2002). Building Sense of Community at a Distance. The International Review of Research in Open and Distributed Learning, 3(1).

Rovai, A. P., \& Jordan, H. (2004). Blended Learning and Sense of Community: A Comparative Analysis with Traditional and Fully Online Graduate Courses. The International Review of Research in Open and Distributed Learning, 5(2).

Schoenfeld-Tacher, R., \& Sims, M. H. (2013). Course Goals, Competencies, and Instructional Objectives. Journal of Veterinary Medical Education, 40(2), 139-144. http://doi.org/10.3138/jvme.0411-047R

Scoles, J. (2018). Researching 'messy objects': how can boundary objects strengthen the analytical pursuit of an actor-network theory study? Studies in Continuing Education, 40(3), 273-289. http://doi.org/10.1080/0158037X.2018.1456416

Sharp, J. G., Hemmings, B., Kay, R., \& Sharp, J. C. (2017). Academic boredom and the perceived course experiences of final year Education Studies students at university. Journal of Further and Higher Education, 9486, 1-27. http://doi.org/10.1080/0309877X.2017.1386287

Snyder, B. R. (1971). The Hidden Curriculum. New York: MIT Press.

Svetsky, S., \& Moravcik, O. (2018). Some Barriers Regarding the Sustainability of Digital Technology for Long-Term Teaching. In Proceedings of the Future Technologies Conference (pp. 950-961). Springer, Cham. http://doi.org/10.1007/978-3-030-02686-8_71

Toppin, I. N. (2011). Video lecture capture (VLC) system: A comparison of student versus faculty perceptions. Education and Information Technologies, 16(4), 383-393. http://doi.org/10.1007/s10639-010-9140-x

van Dijck, J. (2008). Digital photography: Communication, identity, memory. Visual Communication, 7(1), 57-76. http://doi.org/10.1177/1470357207084865

Zawacki-Richter, O., \& Naidu, S. (2016). Mapping research trends from 35 years of publications in Distance Education. Distance Education, 7919(July), 1-25. 
http://doi.org/10.1080/01587919.2016.1185079

Zhu, E., \& Bergom, I. (2010). Lecture Capture: A Guide for Effective Use. CRLT Occasional Papers, 27. 